\title{
Study on Consumer Perception towards Quality of Spices Powder Available in Bangladesh
}

\author{
Sadia Sattar 1,2*, Pabitra Chandra Das',2, Md Sajjad Hossain ${ }^{1,2}$, Kazi Sarower ${ }^{1,3}$, \\ M. Burhan Uddin ${ }^{1}$
}

${ }^{1}$ Department of Food Technology \& Rural Industries, Bangladesh Agricultural University, Mymensingh, Bangladesh ${ }^{2}$ Department of Chemical \& Food Process Engineering, Rajshahi University of Engineering \& Technology, Rajshahi, Bangladesh ${ }^{3}$ Department of Food Technology, Cox’s Bazaar Polytechnic Institute, Cox’s Bazar, Bangladesh

Email: *pinky.bau@gmail.com

How to cite this paper: Sattar, S., Das, P.C., Hossain, M.S., Sarower, K. and Uddin, M.B. (2019) Study on Consumer Perception towards Quality of Spices Powder Available in Bangladesh. Open Journal of Safety Science and Technology, 9, 137-144.

https://doi.org/10.4236/ojsst.2019.94009

Received: September 14, 2019

Accepted: November 8, 2019

Published: November 11, 2019

Copyright (c) 2019 by author(s) and Scientific Research Publishing Inc. This work is licensed under the Creative Commons Attribution International License (CC BY 4.0).

http://creativecommons.org/licenses/by/4.0/

\section{Abstract}

This was a survey-based study and conducted to analyze the findings of questionnaires about the consumer opinion towards the quality of few selected spices powder (turmeric, coriander, chili, cumin and mixed spices) available in Bangladesh, the health effect of low-quality spices powder and the preventive measures as well. From the survey, it was found that on average $90.70 \%$ people believed that the spices powders are not of good quality. Study on the types of adulterants added in the spices powder according to consumers' suspect revealed that addition of low-grade raw spice with high grade was at the top position which was followed by brick dust and sand. Based on consumers' opinion, cancer, chronic nephritis and high blood pressure were the top possible diseases which may associate due to consumption of adulterated spices powder. Implication of Bangladesh Standards and Testing Institution (BSTI) standards, enforcing law and imposing punishment and social motivation of food consumers could be the best preventive measures according to the people's opinion. Finally, this study revealed that the people suspect that the quality of spices powder in Bangladesh is not up to the mark and expect necessary actions against adulteration if found in spices powder.

\section{Keywords}

Spices Powder, Adulteration, Diseases, Preventive Measures

\section{Introduction}

Spices are extensively used for food preparation in the cuisine of Indian subcontinent, among which Bangladesh is a central one. They also provide aroma and 
good taste to the cooked foods as well as they also possess some food value. The Bangladeshi land and climate are favorable for the cultivation of different spices. Traditionally, these spices are crushed to prepare grinded powder, but the present complex socio-economic condition leads to the popularity of readymade spices.

The spices are obtained from large number of different plants. There are about 70 species of spices grown in different parts of the world [1]. The spices can be classified in different ways according to their botanical families, economic importance, method of cultivation or part of component of the plant, such as barks (cinnamon), roots or rhizomes (ginger), flower buds (clove), fruits and seeds (pepper, cardamom). In most cases, spices are very aromatic and may contain large percentage of essential oil from which they derive their main flavoring character. In certain pungent spices (capsicum, ginger, pepper), the non-volatile components are of greater importance to the flavoring effect [2]. In many cases, no single compound is responsible for flavors; a blend of different components, such as alcohols, phenols, esters, terpenes, organic acids, resins, alkaloids and sulphur-containing compounds contribute to the flavor. In addition to flavor containing components, all spices contain the usual components of plant products such as proteins, carbohydrates, fibre, minerals, tannins and polyphenols.

Adulteration is a well-known term defines the addition of any prohibited substance either partially or fully which is noncompliance with health or safety standards as determined by the Food and Drug Administration (FDA). Among food items, spices, due to their inherent nature, great demand and high price, become easy substances for gross adulteration.

As spices are agricultural products, they are prone to microbial spoilage and claimed that due to higher prices of spices powder, there is higher possibility of adulteration with physical and chemical commodities. They are generally adulterated with less expensive materials, e.g. cassia or cinnamon is mixed with a variety of different materials, such as ground hulls from various fruits, sawdust, ground fruit seeds and nutshells, and other readily available waste materials. Ground spices such as curry powder, Garam masala, chilli powder and turmeric powder are others, which are easily adulterated [1].

In Bangladesh, different types of grounded spices powders are available like onion, ginger, coriander, chilli, turmeric, cumin, etc. These powdered spices are commercially processed and packaged by some leading food industries, while some local non-branded industries also exist. Nowadays, women are busy with their carriers, the demand of branded spices powder is increasing gradually. The escalating market of this product implies that in Bangladesh this tradition is increasingly attaining momentum. Although there are few renowned food industries, peoples are always suspicious about these products. But there are still not enough investigations for the quality check of all these branded powdered products. 
Based on these state point of views, this survey-based study was undertaken to fulfill the following objectives: to know consumer opinion on quality of the spices powder, to know the consumers suspect about types of adulterants added in spices powder and disease-associated due to consumption of adulterated spices and to find the consumer thinking about preventive actions to get quality spices powder.

\section{Materials and Methods}

\subsection{Study Site}

As a part of complete research on quality analysis (physical, biochemical, microbial, etc.) of spices powder, this study was undertaken from the Department of Food Technology and Rural Industries, Bangladesh Agricultural University, Bangladesh. A comprehensive survey was completed to know consumer attitude towards spices powder covering the people of different sections of society such as academician, scientists, doctors, researchers, traders and consumers from Dhaka division using a comprehensive questionnaire.

\subsection{Preparation of Questionnaire}

A questionnaire (a copy is available upon request from the corresponding author) was prepared to know the consumer opinion about different selected spices powder (turmeric, chili, coriander, cumin and mixed spices). The questionnaire contained some questions for the consumers including whether the spices powder are adulterated or not, types of adulterants used, disease associated with consumption of adulterated spices and preventive measure against adulteration of spices powder.

\subsection{Data Collection and Preparation}

Prepared questionnaires were distributed among the consumers to know their attitude towards quality of commercial packaged and open non-branded spices powder. Data obtained from the respondents were first transferred to a master sheet, then compiled, coded, tabulated and analyzed in accordance with the objectives of the study, where the positive and negative responses on various questions were identified for statistical calculation.

\subsection{Statistical Analysis}

Statistical measures as number and percentage distribution, range, mean and standard deviation were used in describing different variables. The data were analyzed statistically by using Microsoft Excel (2013) spread sheet.

\section{Results and Discussion}

\subsection{Public Opinion about Status of the Quality of Spices Powder}

The public opinion for the status of quality of the selected commercial and open spices powder is shown in Table 1. From the Table, it was found that for 
Table 1. Survey results of consumer opinion on quality of the spices powder.

\begin{tabular}{cccccc}
\hline \multirow{2}{*}{$\begin{array}{c}\text { Name of the } \\
\text { spice powder }\end{array}$} & \begin{tabular}{c} 
Total \\
\cline { 3 - 6 }
\end{tabular} & respondent & Not of optimum quality product & \multicolumn{2}{c}{ Quality product } \\
\cline { 3 - 6 } & 1000 & 922 & 92.20 & 78 & 7.80 \\
\hline Respondent & Percentage (\%) & Respondent & Percentage (\%) \\
Coriander & 977 & 878 & 89.87 & 99 & 10.13 \\
Chili & 990 & 947 & 95.66 & 43 & 4.34 \\
Cumin & 931 & 800 & 85.93 & 131 & 14.07 \\
Mixed & 982 & 897 & 91.34 & 85 & 8.66 \\
Average \pm SD & $975 \pm 26.62$ & $889 \pm 56.03$ & $90.7 \pm 4.02$ & $87 \pm 32.02$ & $9.00 \pm 3.54$ \\
\hline
\end{tabular}

turmeric powder around 1000 people expressed their opinion and among them, $92.20 \%$ people thought the quality of the turmeric powder. In addition, it is depicted that for coriander, chili, cumin and mixed spices powder around $89.87 \%$, $95.66 \%, 85.93 \%$ and $91.34 \%$ people suspected that the quality of these product may not of good quality. So great alarming suspicious attitude could be seen from this study, but it doesn't indicate that these spices are not superior in their quality, it is just consumer thinking.

\subsection{Public Opinion about Adulterants Types Used in Processed Spices Powders}

Another survey was conducted on the most common adulterants used in the spices powder available in local markets. The respondents were asked by showing few probable adulterants (prefixed) which might be added in corresponding spice powder and the obtained results are shown in Table 2. It is seen that for turmeric powder, around $34.84 \%$ consumers suspected that low grade turmeric may be used with the superior turmeric whereas $32.31 \%$ thought that turmeric powder may be adulterated by mixing brick sand and dust, which was followed by $18.10 \%$ for harmful preservatives, $13.75 \%$ for moisture addition and $1.00 \%$ for others adulteration. Similar adulterants ranking was observed for coriander, chili, cumin and mixed spices powder according to consumer suspection. From the table it is clearly notified that the addition of low grade raw materials or processing of spices with low grade raw spices may have an impact on quality of spices. Beside this, consumer thought birck dust or sand in powder form could get mixed with the spices to make their costing lower and different lower grade preservative mostly color as well. Moisture quantity above the standard level may damage the equality of the spices, which also in think in of consumer. According to ASTA [3] and IISR [4] different adulterants are used in spices to make them cheaper than original one likely color, starch of maize, wheat, tapioca and rice in turmeric, chilly and curry powder; brick powder grit, sand, dirt and filth in chili powder; dung powder and common salt in coriander powder. Beside 
Table 2. Public opinion on adulterants types used in processed spices powders.

\begin{tabular}{|c|c|c|c|c|c|}
\hline \multirow{2}{*}{$\begin{array}{l}\text { Name of } \\
\text { products }\end{array}$} & \multirow{2}{*}{$\begin{array}{c}\text { Total } \\
\text { respondent }\end{array}$} & \multirow{2}{*}{ Type of adulterants } & \multicolumn{2}{|c|}{ Respondent } & \multirow{2}{*}{ Remarks } \\
\hline & & & Number & $\%$ & \\
\hline \multirow{5}{*}{$\begin{array}{l}\text { Turmeric } \\
\text { powder }\end{array}$} & \multirow{5}{*}{1702} & i) Brick dust and sand & 550 & 32.31 & Second \\
\hline & & ii) High moisture & 234 & 13.75 & \\
\hline & & iii) Harmful preservatives & 308 & 18.10 & Third \\
\hline & & iv) Low grade turmeric & 593 & 34.84 & First \\
\hline & & v) Others & 17 & 1.00 & \\
\hline \multirow{5}{*}{$\begin{array}{l}\text { Coriander } \\
\text { powder }\end{array}$} & \multirow{5}{*}{1630} & i) Dust and sand & 536 & 32.88 & Second \\
\hline & & ii) High moisture & 213 & 13.07 & \\
\hline & & iii) Harmful preservatives & 273 & 16.75 & Third \\
\hline & & iv) Low grade coriander & 593 & 36.38 & First \\
\hline & & v) Others & 15 & 0.93 & \\
\hline \multirow{5}{*}{$\begin{array}{l}\text { Chilli } \\
\text { powder }\end{array}$} & \multirow{5}{*}{1755} & i) Brick Dust and sand & 597 & 34.02 & Second \\
\hline & & ii) High moisture & 205 & 11.68 & \\
\hline & & iii) Harmful preservatives & 271 & 15.44 & Third \\
\hline & & iv) Low grade chili & 653 & 37.21 & First \\
\hline & & v) Others & 29 & 1.65 & \\
\hline \multirow{5}{*}{$\begin{array}{l}\text { Cumin } \\
\text { powder }\end{array}$} & \multirow{5}{*}{1466} & i) Dust and sand & 429 & 29.26 & Second \\
\hline & & ii) High moisture & 264 & 18.01 & Third \\
\hline & & iii) Harmful preservatives & 205 & 13.98 & \\
\hline & & iv) Low grade cumin & 556 & 37.93 & First \\
\hline & & v) Others & 12 & 0.82 & \\
\hline \multirow{5}{*}{$\begin{array}{l}\text { Mixed } \\
\text { spices } \\
\text { powder }\end{array}$} & \multirow{5}{*}{1688} & i) Brick dust and sand & 498 & 29.50 & Second \\
\hline & & ii) High moisture & 216 & 12.80 & \\
\hline & & iii) Harmful preservatives & 320 & 18.96 & Third \\
\hline & & iv) Low grade spices & 635 & 37.62 & First \\
\hline & & v) Others & 19 & 1.13 & \\
\hline
\end{tabular}

these different foreign seed powder, color, floral waste, leaves, husks, sudan red may also have uses to make spices powder adulterated. So, consumer perception may be true in case of addition of suspected adulterants.

\subsection{Consumer Perception about Probable Diseases}

As spices are extensively used for preparation of all the household cooked food products in our country, it can be easily assumed that adulteration of this product may cause serious quality problem to the processed food. The probability of disease associated with consumption of food products indicated by 6106 respondents is shown in Figure 1.

According to their opinion, more than nine diseases may be happened due to consumption of adulterated food products. From the study, it is evident that due to intake of adulterated food products, the highest possibility was suffering from 


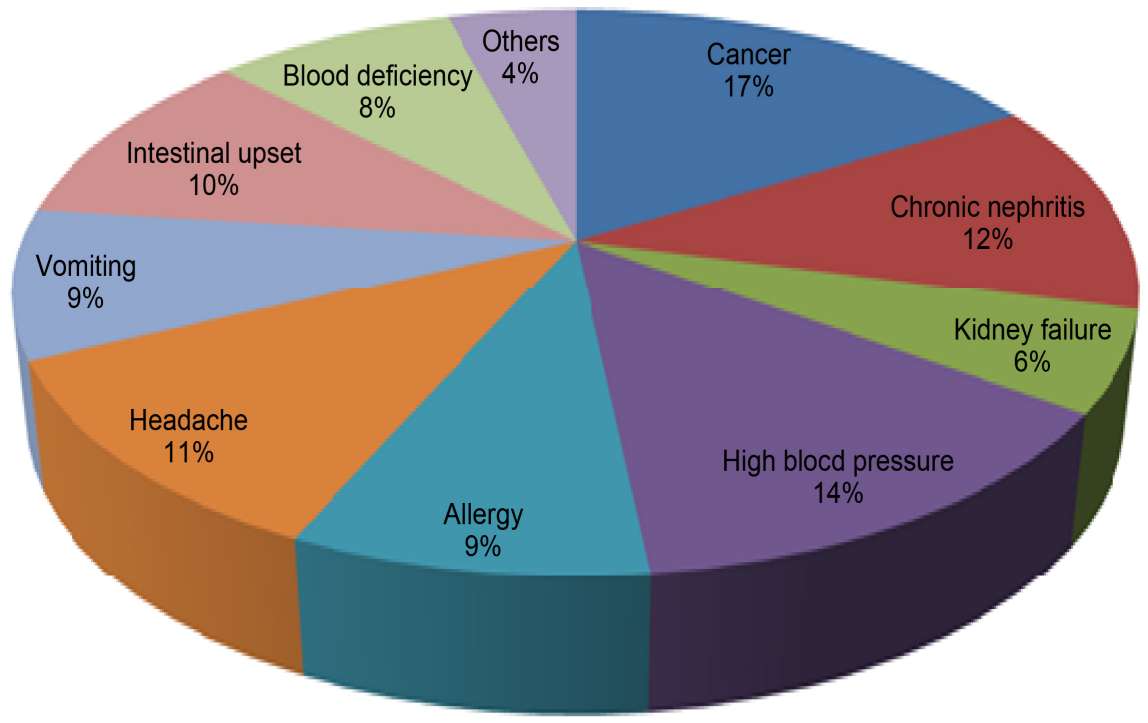

Figure 1. Consumer opinion on possible diseases for adulterated spices consumption.

cancer (16.68\%), which was followed by high blood pressure (13.54\%) and chronic nephritis (12.26\%), headache (11.31\%), intestinal upset (10.49\%) and so on. Adulterated foods intake may cause different serious and life threatening diseases such as asthma, sore throat, larynx constriction, bronchitis, skin infections, allergic reactions, diarrhea, hematuria, circulatory failure, numbness, dizziness, kidney failure, stomach cancer, liver cancer, nervous disorders, etc., [5].

Adulteration of food leads to several heath issues in humans can lead due to eating of adulterated foods [6] [7] and several health hazardsmay cause as a bad effect of adulterated foods consumption likely stomach ache, body ache, anaemia, paralysis, abnormalities of skin and eyes, etc., [8]. So consumer opinions found in this research were in agreement with that of these researchers.

\subsection{Preventive Measures against Spices Adulteration}

Necessary actions against the adulteration of spices may help the consumer to lead a comfortable and healthy life. The preventive measures need to be undertaken to control adulteration in food products indicated by 3572 respondents are shown in Figure 2.

According to the respondents, the best preventive measure should be "Adopting BSTI standard" (22.34\%). The second and third preventive measures should be "Enforcing law and imposing punishment" (21.98\%) and "Social motivation of food consumers" (20.35\%) respectively, followed by strong supervision against spices processors (16.88\%), social motivation for food processors $(16.01 \%)$ and others (2.44\%). Rahman et al. [5] concluded that hundreds of laws are available in the country but not many of them are enforced. However, adoption of rules and regulation, maintaining the provided standard by Bangladesh Standard and Testing Institution may result positively against consumer suspects about spices adulteration. 


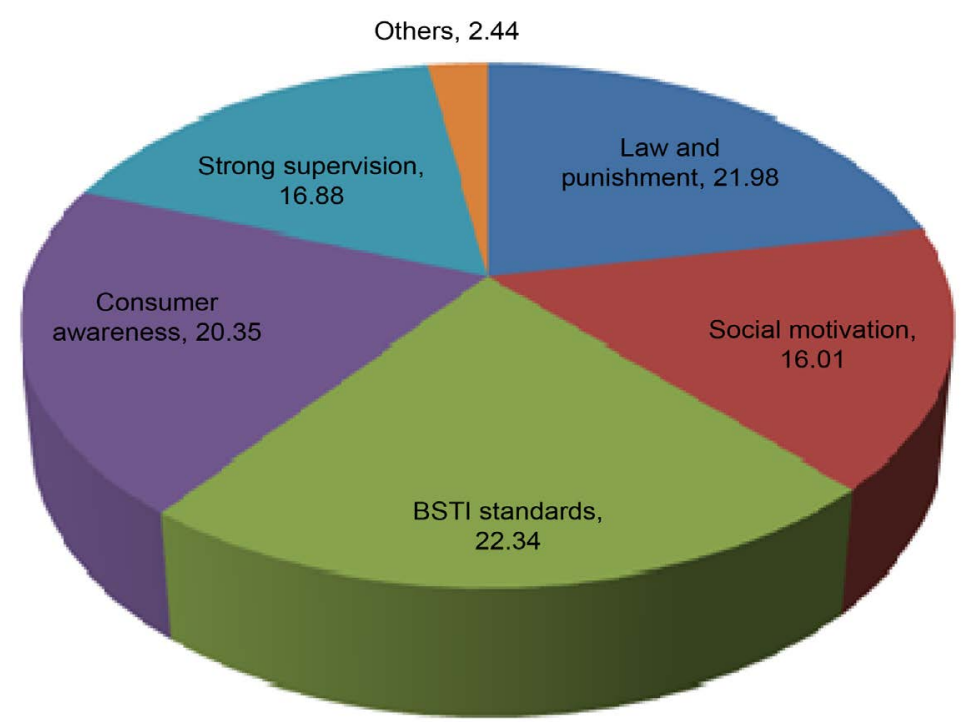

Figure 2. Public opinion towards necessary steps to prevent adulteration.

\section{Conclusion}

Adulteration of spices could be an alarming problem for any country regarding the health issue of the people. This study concluded that most of the people of the country believed that good quality spices powder are not available in the market of Bangladesh and opinioned that different types of adulterant may be used in these products. People also think that these adulterated spices powder may also responsible for different types of diseases including cancer, chronic nephritis, high blood pressure, headache, intestinal problem, allergy, etc. This study also concluded that the processing entity should strictly follow the rules and regulations of the Bangladesh Food Safety Authority (BFSA) and BSTI standards. However, this study can't provide information about the spices powders are adulterated or not, but only represents the people's attitude regarding spices' quality. Further study can be undertaken about the confirmation of presence of any adulterants or quality status of the spices powder available in Bangladesh.

\section{Acknowledgements}

The authors are grateful to the Department of Food Technology and Rural Industries, Bangladesh Agricultural University and Ministry of Science and Technology, People's Republic of Bangladesh for financial and technical support regarding this study.

\section{Conflicts of Interest}

The authors declare no conflicts of interest regarding the publication of this paper.

\section{References}

[1] Manay, N.S. and Shadaksharaswamy, M. (2005) Spices; Foods: Facts and Principles. 
New Age International Pvt Ltd, New Delhi, 322-331.

[2] Heath, H. B. (1977) Flavourings, Condiments and Relishes. In: Desrosier, N.W., Ed., Elements of Food Technology, AVI Publishing Company, Westport, 666-677.

[3] ASTA (American Spice Trade Association) (2004) Spice Adulteration. White Paper, New York.

[4] IISR (Indian Institute of Spice Research) (2007) Spices News.

[5] Rahman, M.A., Sultan, M.Z., Rahman, M.S. and Rashid, M.A. (2015) Food Adulteration: A Serious Public Health Concern in Bangladesh. Bangladesh Pharmaceutical Journal, 18, 1-7. https://doi.org/10.3329/bpj.v18i1.23503

[6] Rao, N.R., Sudhakar, P., Ramesh, V.B. and Gupta C.P. (1989) A Study of Recorded Cases of Foodborne Diseases at Hyderabad during 1984-1985. Journal of Tropical Medicine and Hygiene, 92, 320-324.

[7] Bhatia, V., Swami, H.M., Bhatia M. and Bhatia S.P.S. (1999) Attitude and Practice Regarding Diarrhea in Rural Community in Chandigarh. Indian Journal Pediatrics, 66, 499-503. https://doi.org/10.1007/BF02727156

[8] Shah, R.C., Wadher, B.J. and Reddy, B.G.L. (1996) Incidence and Characteristics of Bacillus Cereus Isolated from Indian Foods. Journal Institute of Food Science Technology, 33, 249-250. 